\title{
Entrevista al Dr. Alejandro Amor, Defensor del Pueblo de la Ciudad Autónoma de Buenos Aires
}

\author{
Revista Derechos en Acción
}

Año 3/Nº 9 Primavera 2018, 591-599

DOI: https://doi.org/10.24215/25251678e244

REDEA: Buen día Dr. Alejandro Amor, gracias por atendernos. Ya se encuentra próximo a finalizar el mandato de Defensor del Pueblo de la Ciudad Autónoma de Buenos Aires. ¿Qué balance puede hacernos desde que tomó posesión de su cargo hasta hoy? A su juicio, ¿Cuáles serían las acciones a destacar y las asignaturas pendientes de la Defensoría en estos últimos años?

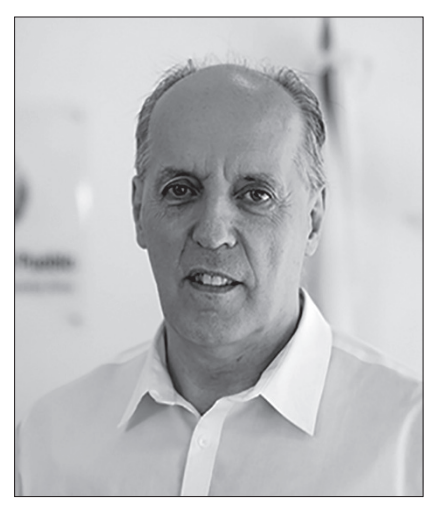

DR.A.AMOR: Lo que destaco de nuestra gestión está relacionado con la expansión de la Defensoría, tanto en nivel de visibilidad como de descentralización. Crecimos en cantidad de sedes y de acciones realizadas en pos de mejorar y promover los derechos de los vecinos y vecinas. En ese sentido, la descentralización fue uno de los ejes claves de este crecimiento, y esto se refleja en la cantidad de reclamos que hemos recibido en este último año. El ingreso de reclamos, la cantidad de vecinos y vecinas que se acercaron a nuestra Defensoría, se fue incrementando año tras año desde que comenzamos, y hoy tenemos alrededor de 80 mil consultas y 50 mil trámites iniciados por año. Pero además logramos fortalecer la imagen de la Defensoría y la cantidad de personas que hoy nos conoce ha crecido en un 50\%. 
La Defensoría del Pueblo de la Ciudad de Buenos Aires siempre se destacó por ser una institución compuesta por profesionales y especialistas de gran trayectoria y mucho prestigio en todas las temáticas, el trabajo articulado y la búsqueda de soluciones con un abordaje multidisciplinario también es un logro institucional que me enorgullece. El crecimiento y perfeccionamiento del Consejo de Mediación, Conciliación y Arbitraje de la casa resuelve el $80 \%$ de los casos que ingresan. En 2018 llevamos más de 2000 casos trabajados en este sistema integrado de resolución de conflictos. Pero además de los casos particulares, mediamos en casos como el reclamo de alumnos escuelas secundarias en el marco de la reforma educativa llamada "escuela del futuro", en donde logramos varios puntos de acuerdo entre los alumnos que se encontraban con las escuelas tomadas y el Ministerio de Educación; la instalación de la carpa docente frente al Congreso Nacional en el marco de un reclamo de aumento salarial, entre otros casos.

También es un avance a destacar el uso que hicimos de la iniciativa legislativa que nos confiere la ley. En los últimos dos años presentamos 61 proyectos de ley ante la legislatura porteña, de los cuales surgieron normas importantes como la Ley Brisa, proyecto que presentamos junto a la ONG La Casa del Encuentro y se transformó en una ley que le otorga una reparación económica a las víctimas colaterales de femicidios, es decir a los niños o niñas que perdieron a su mamá a causa de un femicidio. Este tipo de iniciativas, trabajadas además con distintos actores que representan las necesidades más concretas de los grupos vulnerables, también forma parte de los logros institucional. (Todos los proyectos y las leyes aprobadas están en la web institucional)

Participamos en todas las audiencias públicas, por la causa ACUMAR, por aumentos en las tarifas de servicios públicos esenciales (luz, gas, agua), por aumento de transportes públicos, por las modificaciones de los códigos, como el nuevo Código Urbanístico de la Ciudad. Establecimos mesas de trabajo en temas centrales como la Integración Socio Urbana de la Villa 31. 
Otra cosa a destacar es la participación y todo el trabajo que hicimos junto a los Defensores y las Defensoras de todo el país a través de ADPRA (Asociación de Defensorías del Pueblo de la República Argentina). Nuestro país tiene 53 Defensores y Defensoras del Pueblo provinciales y municipales, y ante la falta de Defensor del Pueblo de la Nación, temas tales como los aumentos en las tarifas de servicios públicos esenciales, la reparación histórica para jubilados y pensionados, las modificaciones en las pensiones por discapacidad, las inscripciones de electrodependientes, las manifestaciones y protestas sociales, entre otros, recaen en la intervención urgente de todas las Defensorías nucleadas en ADPRA. Los Defensores y Defensoras entendimos esta necesidad y es un hecho a destacar que se pueda trabajar en conjunto, sumando esfuerzos y complementando las necesidades de cada región, para encontrar propuestas para resolver las problemáticas de los argentinos en cada rincón del país. Todavía falta Defensoría del Pueblo en Mendoza, Santa Fe, San Luis y Entre Ríos, eso es una asignatura pendiente sin ninguna duda.

Otro avance fue la observación de la Defensoría en todas las manifestaciones y protestas sociales en cumplimiento de la misión que la Oficina Regional para América del Sur del Alto Comisionado de las Naciones Unidas para los Derechos Humanos no encomendó para la aplicación de las Directrices para la Observación de Manifestaciones y Protestas Sociales a las Defensorías del Pueblo de la región. En ese marco la Defensoría se ha transformado además en una mediadora entre las organizaciones que participan de las protestas y el Gobierno porteño, con un trabajo en conjunto para garantizar el desarrollo pacífico de las manifestaciones y evitar conflictos.

REDEA: Una de las preocupaciones de su gestión fue llevar adelante una política de descentralización, de allí la creación de distintas sedes en diferentes puntos de la ciudad. Podría comentarnos como fue esa experiencia. ¿Considera que el habitante de la ciudad de Buenos Aires sabe de la existencia de la Defensoría del Pueblo y que puede acudir a Ustedes en defensa de sus derechos? 
DR. A. AMOR: Creemos que el acceso a la información es la base para que los vecinos tomen conocimiento de cuales son sus derechos y puedan reclamar ante alguna vulnerabilidad. Por eso hemos puesto mucho empeño en esta misión de promoción y difusión de derechos, que además nos da la Constitución y la Ley 3 de la Ciudad en su artículo número 2.

Hemos trabajado muy fuertemente estos años en expandir y hacer llegar la existencia de la Defensoría a la mayor cantidad posible de personas, y la descentralización ha sido sin dudas uno de los principales ejes de nuestra gestión para poder tener presencia en cada una de las quince comunas. Actualmente tenemos 34 sedes, además de estar presentes en todas las villas de la Ciudad.

Nos preocupa lo que pasa en toda la Ciudad de Buenos Aires, tanto lo que le pasa a quienes viven acá, como con los que vienen a trabajar o a pasear. Creemos que los problemas no tienen el tamaño que le podemos dar nosotros, sino que tienen el tamaño de la persona que los padece. Por eso no hay problemas chicos o grandes. El problema tiene la dimensión que le da quién lo tiene. Nuestro rol es tomar a todos los problemas de la misma manera, y estar en los lugares donde los vecinos y las vecinas de la Ciudad de Buenos Aires nos necesitan para resolverlos.

A partir de esto forjamos una relación de ida y vuelta con los vecinos y vecinas con escucha y observación directa de las problemáticas de cada barrio, de cada comuna. Creo que todos los funcionarios tenemos que acostumbrarnos a salir de los escritorios, caminar, tomar contacto con la gente y escuchar las críticas y los enojos por parte de los vecinos. Tenemos que estar en la calle, para hacernos cargo de los problemas de la gente.

Otra política de descentralización fue la apertura de redes sociales como vía válida de denuncia. A través de un centro de contactos con personal capacitado para dar respuesta por esos canales, recibimos a través de facebook, twitter e instagram cientos de consultas diarias que dan inicio a trámites 
abreviados, que son aquellos que se resuelven con una gestión inmediata y otros que llevan más tiempo para su resolución.

Además fortalecimos la tarea de promoción y difusión de derechos. Hoy tenemos 32 guías de derechos en las que damos acceso a información básica de temas como: Derechos de inquilinos, Consorcios, consumidores, telefonía celular, derechos sexuales y reproductivos, entre otras. Estas guías se reparten todos los días en distintas esquinas de la Ciudad de Buenos Aires, donde además se toman reclamos de los vecinos y se responden consultas.

También pusimos al aire diferentes programas de radio: "Tenés quien te defienda", que se hace junto con el equipo de la Coordinación Operativa de villas y se emite en radio zonales ubicadas en (Bajo Flores, Barrio Fátima, La Boca, Villa 15, Villa Soldati, Cildañez y el Playón de Chacarita); y el programa "La Defensoría con vos", que se emite todos los sábados por Radio La Red. Ambos programas también funcionan a modo de puente con los vecinos ya que a través de los oyentes que se comunican recibimos alrededor de 200 denuncias semanales.

REDEA: Tenemos entendido que Ud. ha participado en su carácter de Defensor del Pueblo en distintas audiencias públicas referidas tarifas de servicios públicos. ¿Nos podría comentar esas experiencias y su opinión acerca de estos mecanismos de participación ciudadana?

DR.A.AMOR: Desde la primera audiencia celebrada con motivo de aumento de las tarifas en el año 2016, nos llegó institucionalmente la invitación a todos los Defensores del Pueblo de la República Argentina. Nosotros, como Defensores del Pueblo tenemos un rol: justamente una de nuestras responsabilidades es la defensa de los derechos de los usuarios y consumidores. Pero en el aumento de tarifas había algo más, porque se trata de servicios públicos esenciales que, en el caso del agua por ej, además es un derecho humano fundamental. Allí veíamos que se vulnerarían derechos básicos de las personas, en materia de tarifa social, electrodependientes, suspensión de servicios. 
Las audiencias públicas sirven para que las personas nos expresemos. Y para poder explicar, frente a la renovación de un cuadro tarifario cuál es la posición de cada actor. Los cuadros tarifarios no se resuelven nada más a partir de planillas, donde se definen números para que cierren las cuentas finales. También hay que considerar, con mucha atención, las realidades particulares y regionales, las realidades y particularidades de las familias, de los usuarios que no son clientes sino personas.

Hemos participado de todas las audiencias y en todas hemos intentado hacer llegar lo mismo que escuchamos de parte de la gente: que cada vez destinan más porcentaje de sus ingresos al pago de tarifas, en muchos casos que ya no pueden pagar todos los servicios y deben elegir entre luz, gas o agua, que es difícil acceder a la tarifa social, negocios y PYMES que tienen que cerrar o despedir empleados por el incremento en los costos, entre otras cosas. Llevamos cada una de estas problemáticas, cientos de casos concretos, casos testigos y otros de urgente resolución como los de electrodependientes, a las audiencias. Pero también armamos una mesa de trabajo con las empresas y el Ministerio de Energía, con el Ministro Aranguren teníamos reuniones permanentemente en las que los Defensores les llevábamos las preocupaciones, propuestas y reclamos. De esa mesa salen muchas soluciones.

Creo que la realización de las audiencias públicas se constituye como un requisito indispensable que otorga validez a los actos que se atacan. En concreto su falta de realización afecta directamente los intereses de los usuarios del servicio público. A pesar de que no sean vinculantes deben ser tomadas en cuenta en la resolución final y es obligación de los funcionarios que notamos fallas participar de ellas.

REDEA: ¿Como ha sido la recepción jurisprudencial respecto de su competencia en la defensa de derechos colectivos?

DR. A. AMOR: La Constitución Nacional, reformada en 1994 y la Constitución de la Ciudad de Buenos Aires, 1996, contienen textos sobresalientes en materia de derechos colectivos. 
En los últimos 35 años las sociedades han cambiado muchísimo. El Derecho constitucional debe contener normas que sean suficientemente solventes y elásticas para dar cobertura a nuevas situaciones, que, en general, son producto de los cambios incesantes en la ciencia y la tecnología.

La Defensoría del Pueblo de la Ciudad de Buenos Aires es un órgano constitucional. Su tarea se remonta a 1998. La defensa de los derechos y también de los bienes colectivos, ha constituido, constituye y constituirá una instancia básica de la actividad institucional.

Los derechos colectivos son el género, pero en su seno descansan diferentes especies que abrazan a diferentes individuos como asimismo diferentes intereses protegidos. Los primeros derechos colectivos han nacido en la fragua del Derecho del Trabajo, en la primera mitad del siglo XX. Luego, la dinámica comunitaria ha exigido la creación de nuevos modelos, porque, los derechos colectivos son una invención. Precisamente esa invención provoca que la Defensoría del Pueblo de la Ciudad de Buenos Aires atienda, respalde, gestione y tutele los derechos colectivos durante las 24 horas de los 365 años del año.

"Tenés quien te defienda" es una consigna de la tutela constante e irrenunciable de los derechos colectivos, en cualquier ámbito en cuyo ámbito se discutan. Me refiero a la defensa en lo social, lo ambiental, las relaciones de consumo, servicios públicos, educación y salud, solamente por mencionar algunos aspectos.

Nuestra tarea, por tanto, se deduce de la competencia asignada por el artículo 137 constitucional y de allí en adelante se cumple de muy diferentes maneras: atenciones, patrocinios, recomendaciones, acciones judiciales, proyectos de ley.

Puedo asegurar que, para el estudio de los derechos colectivos en la Ciudad de Buenos Aires, la Defensoría posee un repertorio amplísimo fundado en su actividad institucional, tal como he detallado.

REDEA: En su opinión, ¿cómo evalúa la posición de la Corte Suprema de Justicia de la Nación en ese tema en la causa "CEPIS" 
en relación al Defensor del Pueblo de la Provincia de Buenos Aires?

DR.A.AMOR: Siempre propongo el reconocimiento más amplio de la legitimación de las Defensoría para la defensa de los derechos individuales, sociales y colectivos que se encuentran en el abanico de su competencia. Toda restricción a la legitimación conlleva una restricción a un derecho, porque impedirá la discusión sobre su contenido y los alcances de su protección constitucional.

REDEA: La Defensoría del Pueblo a nivel nacional se encuentra vacante desde el año 2009. ¿Qué opinión le merece esta situación de acefalía?

DR. A. AMOR: La Constitución es un texto que alberga la decisión de los ciudadanos de un pueblo, representados por los convencionales constituyentes. Todos los países del mundo tienen una Constitución, aunque el grado de cumplimiento o realización de los enunciados normativos nunca será completo. Sin embargo, todas las prescripciones de la Constitución deben ser obedecidas y cumplidas.

Particularmente, cuando se crean órganos, como el Defensor del Pueblo, es porque se determina que exista un servidor público que cumpla la misión institucional.

No hay razones que justifiquen la vacancia. Lo he dicho en repetidas ocasiones. También lo hemos sostenido desde ADPRA (Asociación de Defensores del Pueblo de la República Argentina). En 2015, previoalballotage presidencial, realizamos desde ADPRA, una carta compromiso exhortando a ambos candidatos -Macri y Scioli- para que cubrieran -una vez asumido su mandato- las Defensorías que se encontraban vacantes, fundamentalmente la Defensoría de la Nación y la Defensoría del Niño, Niña y Adolescente.

Hay muchas situaciones a nivel nacional que requieren que esté designado el Defensor del Pueblo de la Nación, las audiencias 
públicas de las que hablábamos anteriormente son un ejemplo. En este último tiempo, con ADPRA hemos intentado llenar el vacío que implica que esta Defensoría se encuentre acéfala.

Hay cosas que se definen desde el Estado Nacional. En los casos en los que tiene competencia la Nación, a las Defensorías locales nos niegan en la Justicia la posibilidad de presentarnos, por no tener representatividad. En esos casos, solo puede intervenir la Defensoría del Pueblo Nacional, por eso es tan necesaria.

Hay que trabajar y resolver la situación de acefalía que pronto cumplirá una década.

Me parece que fuera quien fuere que sea designado Defensor del Pueblo de la Nación es importante que se asuma la responsabilidad de proponer una nueva ley para la designación este cargo, ya que la ley vigente es previa a la Constitución de 1994 y ya queda desactualizada. Creo que, por ejemplo, es necesario incorporarle la iniciativa legislativa que es una herramienta fundamental de la cual también carece el defensor del pueblo de la nación, y que establezca un procedimiento claro y transparente a toda la ciudadanía argentina. 